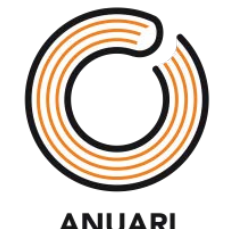

DE BIBLIOTEQUES,

LLIBRES I LECTURA

Jaume Centelles

jcentell@xtec.cat

Mestre i bibliotecari escolar

\title{
LA LECTURA ENTRE ELS INFANTS \\ I ELS JOVES A CATALUNYA (2018-2019)
}

LA LECTURA ENTRE LOS NIÑOS
Y LOS JÓVENES EN CATALUÑA (2018-2019)

READING AMONG CHILDREN AND ADOLESCENTS IN CATALONIA (2018-2019) 


\section{RESUM | RESUMEN | ABSTRACT}

En aquest capítol es fa palès un cert estancament del grau d'assoliment de les competències lectores per part dels infants $i$ joves, i es reflexiona sobre algunes de les possibles causes d'aquesta inèrcia conformista que ens porta a un «anar fent» que ens impedeix aprofitar el potencial humà del país.

També es relacionen alguns plans institucionals de suport a la lectura, la consolidació d'activitats reeixides -jornades, congressos, grups de treball- que mostren interès de fer de la lectura una pedra angular de l'educació i s'apunten algunes idees o situacions que ens allunyen de l'optimisme que hauria de motivarnos, si és que ens volem constituir definitivament com a societat lectora.

En este capítulo se evidencia un cierto estancamiento del grado de consecución de las competencias lectoras por parte de los niños y jóvenes, y se reflexiona sobre algunas de las posibles causas de esta inercia conformista que nos lleva a un «ir tirando» que nos impide aprovechar el potencial humano del país.

También se relacionan algunos planes institucionales de apoyo a la lectura, la consolidación de actividades exitosas -jornadas, congresos, grupos de trabajo- que muestran interés de hacer de la lectura una piedra angular de la educación y se apuntan algunas ideas o situaciones que nos alejan del optimismo que debería motivarnos, si lo que queremos es constituirnos definitivamente como sociedad lectora.

This chapter highlights a certain stagnation in the reading skills of children and young people, and reflects on some of the possible causes of this inertia which, in our view, is stifling the development of the country's human potential.

We discuss some of the institutional plans put forward to promote reading and the consolidation of successful activities such as workshops, conferences and working groups that aim to make reading a cornerstone of education. We also highlight certain ideas or situations that pose a challenge to the optimism that should motivate us if our aim is to establish ourselves definitively as a society that stimulates reading.

Lectura infantil i juvenil, Plans de promoció de la lectura, Informe PISA, Proves PIRLS

PALABRAS CLAVE:

Lectura infantil y juvenil, Planes de promoción de la lectura, Informe PISA, Pruebas PIRL

Reading skills, Children and young adults, PISA report, PIRLS tests 


\section{PRESENTACIÓ}

Howard Gardner, el psicòleg americà conegut per la seva teoria de les intel-ligències múltiples, quan esmenta la lingüística fa referència a la capacitat de conèixer el llenguatge i l'expressió verbal, l'ús de les paraules per comunicar i expressar emocions.

Gardner també ens recorda sovint el període de prova que han de tenir tots els projectes per poder-los valorar. Parla de la "dècada» com a mesura de temps idònia per saber si un programa ha resultat exitós o no. És un pensament assenyat perquè la distància sempre ajuda a comprendre $i$ a veure amb millor perspectiva què s'està fent.

És un pensament, però, que sembla no tenir massa predicament entre la classe dirigent $\mathrm{i}$, així, solem comprovar (amb certa tristesa) com s'inicien projectes, es dicten ordres, s'anuncien grans canvis, etc., que als tres o quatre anys s'esvaeixen per manca d'interès o de pressupost, $i$ es presenten altres tendències (novíssimes i definitives, és clar!).

Estem assistint, en els darrers temps, a l'efervescència d'aquestes noves idees (o velles, disfressades de noves) que ens fan replantejar la manera de fer als centres, les relacions amb els alumnes, amb les famílies, l'organització interna, etc.

És, cada cop més freqüent, comprovar com, per exemple, les parets de les aules es tornen blanques per influència dels pensaments i observacions de la neurociència. També veiem com algunes biblioteques escolars (prou migrades habitualment) estan reconvertint-se en espais que colonitzen o es distribueixen per tot el centre (passadissos, racons, biblioteques d'aula) en una nova tendència que sota el paraigües del que s'anomena ambients de treball està eliminant el concepte de biblioteca general d'escola.

Uns altres models educatius van apareixent - de vegades amb suport econòmic d'entitats privades-, com les aules de futur i noves tecnologies basades en el projecte d'smart classroom, o les flipped classroom, un altre model pedagògic que transfereix el procés de treball de determinats processos de treball fora de l'aula per permetre potenciar l'ús del temps i l'experiència docent per a l'adquisició i el coneixement d'una altra manera.

També passa que, de vegades, la feina ben feta, en mans de persones responsables i conscients que el que fan és útil i necessari, manté un recorregut dilatat en el temps. És el cas d'aquest ANUARI DE BIBLIOTEQUES, LLIBRES I LECTURA que gràcies a la col-laboració dels autors, la constància dels editors i el suport tècnic i econòmic d'algunes institucions, arriba a la sisena edició. Dotze anys que farien feliços els seguidors de Howard Gardner, segur.
Estem veiem com algunes biblioteques escolars

(prou migrades habitualment) estan

reconvertint-se

en espais que

colonitzen o es

distribueixen per

tot el centre 
No va ser fins a la segona edició (2012) que es va introduir el capítol «La promoció de la lectura a l'escola». Allà, Ana Díaz-Plaja (Universitat de Barcelona) i Àlex Cosials (Fundació Jaume Bofill) es feien ressò de les diverses iniciatives que es van dur a terme en el bienni 2010-2011 per millorar la competència lectora. Apuntaven la preocupació i l'interès que es generava a la comunitat educativa, a partir dels nous currículums i l'enfocament competencial, els informes PISA i altres indicadors. Feien menció, també, de la implementació progressiva dels PLEC (plans de lectura de centre), la preocupació del Departament d'Ensenyament mitjançant projectes veterans com ara El Gust per la Lectura o el Programa de Biblioteca Escolar Puntedu, així com la creació de noves iniciatives com, per exemple, Impuls de la Lectura.

Ara, deu anys després, alguns d'aquells programes s'han anat esllanguint o han desaparegut i pel camí n'han aparegut d'altres que també s'han evaporat com si fossin fills d'una modernitat gasosa, recordant la metàfora encunyada per Zygmunt Bauman.

La part més positiva és que com a societat tenim un teixit molt ampli d'entitats i persones que creuen en les bondats d'una població lectora, acollidora i crítica. Aquests grups de treball, entitats més o menys potents i $\mathrm{d}$ 'altres amb bon suport econòmic, i persones compromeses amb la lectura, fan una tasca immensa. Funcionen amb entusiasme (paraula clau) i abasten fins on les seves possibilitats els ho permeten. Col-lectius d'ensenyants de les comarques catalanes, fundacions com la Bofill, agrupacions d'entitats com el Consell Català del Llibre Infantil i Juvenil (ClijCAT), editorials, autors, editors, mestres, bibliotecaris, grups de teatre, ajuntaments, diputacions, etc., tots ells són imprescindibles.

El bienni que comentem -2018-2019- segueix el camí dels anteriors. $\mathrm{Hi}$ ha una inèrcia que, com a la pel-lícula de Fellini, $E$ la nave $v a$, fa que les oportunitats de lectura, la vida al voltant de llibre en forma de presentacions, premis, obertura de noves llibreries, resultats més o menys discrets en les proves que es passen i poca presència de la lectura als mitjans, ja sigui premsa escrita ja sigui ràdio o televisió, continuï un camí discret amb pujades i baixades més o menys costerudes i que no acabi de trobar la velocitat que seria idònia per a una societat com la nostra. N'hi ha prou de mirar el que passa a països amb nivell econòmic similar al nostre per adonar-nos que podríem estar molt millor. Per això, estaria bé que hi hagués un estament oficial que s'encarregués de capitalitzar tot aquest potencial i facilités les connexions entre tothom.

\section{Com a societat tenim un teixit molt ampli d'entitats $i$ persones que creuen en les bondats d'una població lectora, acollidora i crítica}

La vida al voltant del llibre continua un camí discret amb pujades i baixades més o menys costerudes i no acaba de trobar la velocitat que seria idònia per a una societat com la nostra 


\section{LA LECTURA ENTRE ELS INFANTS I ELS JOVES}

\subsection{Plans de lectura d'àmbit nacional}

\section{Pla de lectura 2020}

Continuen algunes accions del Pla, amb la intenció d'afavorir l'hàbit de la lectura mitjançant campanyes de sensibilització ciutadana, com la de «Fas 6 anys. Tria un llibre». El pressupost emprat per a les diferents accions és prou generós i abasta molts àmbits: reconeixement i suport als autors, il.lustradors i traductors; noves línies d'ajut als llibreters; impuls $d^{\prime}$ ambicioses iniciatives firals nacionals $i$ internacionals amb els editors. La convocatòria d'un nou pla per a la construcció i la renovació de biblioteques o per a la renovació de fons bibliogràfics són algunes de les accions més destacades.

Destaca l'enfortiment constant de les biblioteques públiques catalanes que, any rere any, augmenten el nombre d'usuaris. Estem en moments de canvi i és necessària una coordinació interdepartamental i una bona planificació de les polítiques culturals que incideixin en el foment lector. Una lectura acurada del Pla d'actuació (els objectius, els instruments per assolir els objectius, el pressupost assignat i les accions estructurals) fa la sensació que s'estan fent avenços. Caldria, emperò, ser capaços de tenir en compte el món educatiu i sorprèn la poca presència del Departament d'Educació. El Pla queda coix perquè allà on es treballa més per l'equitat, allà on els infants $i$ els joves tenen tots les mateixes oportunitats, és a les escoles $i$ instituts.

El Pla preveu accions de prestigi (Sant Jordi, patrimoni immaterial de la humanitat; acords i convenis amb mitjans de comunicació per la presència d'espais de foment de la lectura, subvencions per a la producció i la difusió de continguts audiovisuals de foment de la lectura a través dels mitjans de comunicació, acords amb les revistes culturals, la Nit de la Lectura, premi de fotografia "Compromís amb la lectura», etc.) però en queden al marge accions amb el Departament d'Educació, tal com es fa amb el Departament d'Empresa i Coneixement, el Departament de Territori i Sostenibilitat, el Departament de Salut, el Departament de Treball, Afers Socials i Famílies o el Departament de Justícia.

$\mathrm{Si}$, com es pretén, es tracta de despertar vocacions lectores, escriptores i intel-lectuals en un pacte per la lectura amb la ciutadania capaç de vertebrar una societat més desenvolupada, més justa i, en definitiva, més humana, s'haurien de tenir en compte els mestres i professors, a través dels seus representants o associacions i els moviments d'ensenyants que hi ha escampats per tot el territori.

\section{Destaca}

l'enfortiment

constant de les

biblioteques

públiques catalanes

que, any rere any, augmenten el nombre d'usuaris 


\subsection{Proves de competència lectora: resultats i anàlisi}

\section{- Proves d'avaluació de les competències bàsiques a sisè de primària i a quart d'ESO}
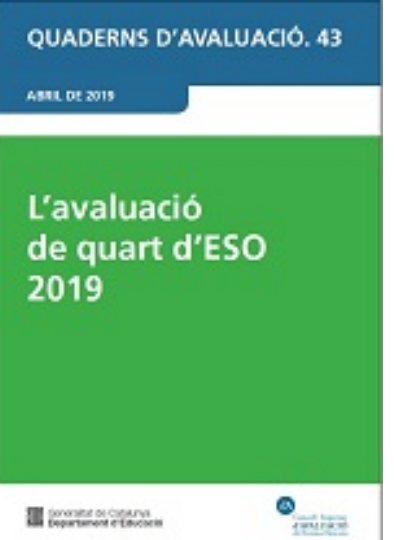

Els resultats de les diferents proves externes d'avaluació de les competències bàsiques presentats el mes de juliol de 2019 evidencien una consolidació en la qualitat i en l'equitat dels resultats a la finalització dels ensenyaments obligatoris. Segons va informar en una nota de premsa el secretari de Polítiques Educatives, Carles Martínez, "es constata un sistema educatiu de qualitat $\mathrm{i}$ que consolida l'equitat cada cop més». No arriba al $15 \%$ el percentatge màxim d'alumnat que no pot assolir una competència.

En la mateixa roda de premsa, el secretari de Polítiques Educatives també va destacar que existeix una relació directa entre determinats elements i els resultats educatius. En aquest sentit, va exposar que "hi ha tres elements que fonamenten la nostra política educativa: tenir professorat competent i compromès, que és peça clau per tenir millors resultats; el lideratge pedagògic dels equips directius, i la necessitat de treballar sempre per projectes per donar coherència a la pràctica educativa del centre». Segons va afegir el mateix secretari, el projecte educatiu del centre ha de donar continuïtat a aquests tres elements.

Com a novetat s'ha incorporat una experiència pilot de l'avaluació oral a quart d'ESO, una de les competències més fràgils i que es treballa menys. $S^{\prime}$ ha dut a terme en cinquanta-un centres educatius i ha afectat mil cinccents alumnes. S'ha avaluat la llengua catalana, la llengua castellana i la Ilengua anglesa. Els resultats han estat bons i la premsa se n'ha fet ressò. La puntuació mitjana global de l'expressió oral en llengua catalana (72,9 punts) i llengua castellana (73,7 punts) supera els setanta punts.

\section{- Proves PISA (programa internacional per a l'avaluació d'estudiants)}

Els resultats de les proves es coneixen un o dos d'anys després d'haver-les fet i els resultats del PISA 2018 es van fer públics el dia 3 de desembre de 2019. El dia 15 de novembre, però, al portal del PISA de l'OCDE hi va aparèixer una nota en què s'informava de l'ajornament dels resultats de comprensió lectora d'Espanya i de les comunitats autònomes per problemes tècnics detectats. Només es van publicar els resultats obtinguts en la competència científica i la competència matemàtica.
Els resultats de les

diferents proves externes d'avaluació evidencien una consolidació en la qualitat i en l'equitat dels resultats a la finalització dels ensenyaments obligatoris 


\section{ESTUDIS I RECERCA}

\subsection{Docència}

\section{- Màster internacional en Llibres i Literatura Infantil i Juvenil}

Organitzat per la UAB, han tingut lloc l'onzena i dotzena edicions, adreçades a professorat d'educació primària $i$ secundària $i$ a bibliotecaris $i$ documentalistes, així com a mediadors i promotors culturals, educadors del lleure, gestors culturals i professionals del món de l'edició. Consta de seixanta crèdits i s'imparteix de manera semipresencial. La nòmina del professorat és molt àmplia i la formació permet accedir al títol de màster de la Universitat Autònoma de Barcelona.

\section{Curs al Vallès Occidental}

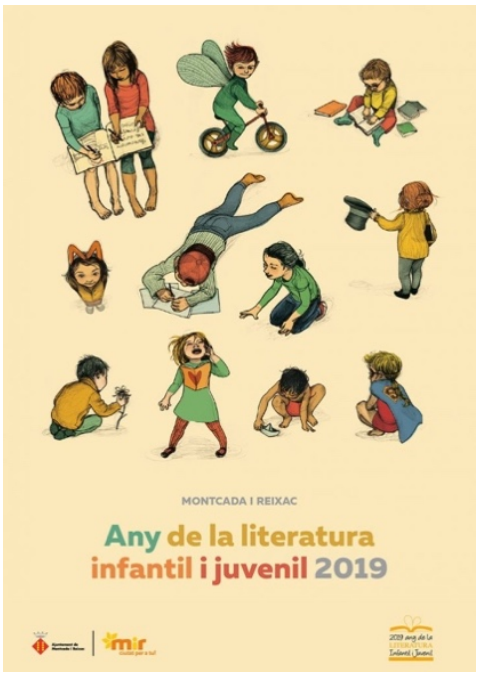

Les Biblioteques de Montcada i el Centre de Recursos Pedagògics del Vallès Occidental VI han organitzat un curs, reconegut pel Departament d'Educació, relacionat amb l'Any de la Literatura Infantil i Juvenil.

El cicle inclòs dins del Pla educatiu d'entorn de Montcada i Reixac constava, a més, de sessions mensuals que permetien abordar diferents temàtiques: I'itinerari lector a l'escola, la dinamització de la biblioteca escolar a primària i a secundària, la lectura a l'institut, les directrius internacionals en aquesta matèria, les competències literàries i la tertúlia a l'aula, l'elaboració de projectes engrescadors i potents per a les biblioteques escolars, les novetats literàries del moment, etc.

\section{- Escola d'Estiu de Literatura Infantil i Juvenil}

Organitzades per la Universitat de Vic i l'Abadia de Montserrat han tingut lloc la novena (2018) i la desena (2019) escoles d'estiu.

La del 2018 va estar centrada en l'oralitat. El títol «Festa, joia i cançó en la literatura infantil $i$ juvenil» feia referència a un aspecte que va permetre reflexionar sobre el valor de la transmissió oral de la literatura per a infants i joves i la seva funció cultural i social.

La del 2019 va ser especial perquè feia deu anys de l'inici de les escoles d'estiu i es va voler celebrar homenatjant Josep Massot, monjo de Montserrat, historiador, filòleg i figura molt rellevant de la cultura catalana. La seva labor com a director de l'editorial Publicacions de l'Abadia de
L'any 2019

I'Escola d'Estiu de

Literatura

Infantil i Juvenil,

organitzada per la

Universitat de Vic i

I'Abadia de

Montserrat, va

celebrar la

desena edició 
Montserrat ha estat incansable i molt destacada en l'edició de llibres per a infants $i$ joves.

\subsection{Projectes i grups}

Dels diferents col-lectius que es reuneixen periòdicament per investigar sobre la lectura, en destaquem els següents:

- El GRETEL és el Grup de Recerca de Literatura Infantil i Juvenil i Educació Literària adscrit a la Universitat Autònoma de Barcelona. El seu objectiu principal de recerca és l'ús dels llibres infantils i juvenils per als aprenentatges literaris a l'escola obligatòria.

- L'Associació de Mestres Rosa Sensat fomenta i promou grups de treball en els quals els mestres poden compartir experiències, fer recerques $i$ proposar accions per millorar la qualitat de l'educació al nostre país. Alguns dels grups de treball tenen relació amb la lectura. N'hi ha amb un llarg recorregut com el seminari de bibliografia infantil i juvenil Quins Llibres i d'altres de més recents com II-lustrem-nos. El resultat del seu treball es plasma en publicacions com 99 invitacions a la lectura. Activitats i propostes per crear, compartir i gaudir amb els llibres del grup Passió per la Lectura o Sense paraules. Sis tallers de lectura d'àlbums sense mots per a totes les edats d'Emma Bosch, premi Marta Mata de pedagogia, 2019.

- El Bib.Botó és un grup de treball del Col-legi Oficial de BibliotecarisDocumentalistes de Catalunya (COBDC) que es reuneix periòdicament a la llibreria barcelonina Al-lots Petit Príncep per comentar les novetats editorials aparegudes al sector.

- El Grup de treball de biblioteques escolars del COBDC, coordinat per Júlia Baena, se centra a posar en valor la biblioteca escolar dins els centres educatius: infantil, primària i secundària, així com la figura del bibliotecari escolar.

\subsection{Treballs i tesis}

De les tesis presentades en aquest període, en destaquem la següent: $A$ través del nuevo milenio y lo que el lector literario encontró allí: caracterización de la narrativa infantil contemporánea para lectores de 8 a 10 años, presentada per Karla Fernández de Gamboa l'11 d'octubre de 2018 i dirigida per Teresa Colomer (Universitat Autònoma de Barcelona).

Diferents col·lectius es reuneixen periòdicament per investigar sobre la lectura 


\section{DIFUSIÓ | DIVULGACIÓ}

\subsection{Congressos, seminaris i reunions científiques}

En aquest període s'han continuat fent les trobades, jornades i reunions que es duen a terme regularment i se n'han afegit de noves, fruit del dinamisme i de l'interès que la lectura mou a casa nostra. En destaquem les següents:

\section{- IV Jornada Literatura i Educació}

Organitzada per l'Associació de Mestres Rosa Sensat, estava prevista per al febrer de 2019 sota el lema «Llegim, sentim, fem poesia a l'aula» i volia centrar-se en el paper de la poesia en l'educació contemporània. Els ponents convidats havien de ser Felipe Munita, Salvador Comelles, Emma Bosch, Andreu Galan, Glòria Bordons i Dani Espresate. Finalment es va cancel-lar per manca d'inscripcions.

\section{- Món Llibre}

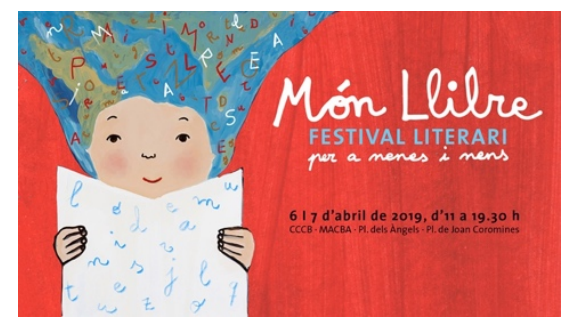

Món Llibre és un festival que està força arrelat a la tradició literària entre les famílies de Barcelona i rodalies. Mantenint l'essència i el nucli de collaboradors ofereixen mirades diferents de tot allò que significa apropar els infants als llibres. Des de l'organització - Institut de Cultura de l'Ajuntament de Barcelona, amb la collaboració del Servei de Biblioteques de Barcelona, el CCCB i el MACBAbusquen propostes noves i engrescadores que contribueixen a fer del Món Llibre un referent del món de la literatura infantil i juvenil. Cal assenyalar, especialment, la participació majoritària de la mainada de menys de tres anys.

L'any 2018 va tenir lloc la catorzena edició i, entre d'altres, es va poder gaudir de l'espectacle de titelles, imatge i dansa del gos Molsa o el clàssic Frankenstein adaptat al llenguatge del teatre d'ombres.

La programació escènica de Món Llibre 2019 va oferir una línia d'espectacles de noves tendències, propostes que transformen els contes clàssics gràcies a la tecnologia i els llenguatges creatius i escènics més contemporanis. Va ser el cas de Pinocchio, de Roseland Musical, un espectacle amb projeccions $i$ efectes visuals $i$ sonors que converteix el famós ninot de fusta en una criatura feta de material reciclat, o d'Alícia i les ciutats invisibles, d'Onírica Mecànica, una proposta innovadora de gran potència visual.
S'han afegit noves trobades, jornades i reunions a les que es duen a terme regularment 


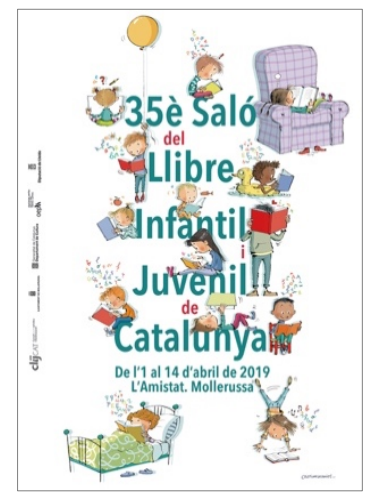

La ciutat de Mollerussa va acollir els salons del llibre infantil i juvenil de Catalunya, com sempre, molt ben organitzats pel ClijCAT i l'Ajuntament de Mollerussa, a través de la Biblioteca Comarcal Jaume Vila.

L'any 2018, el lema va ser "L'aparador de les meravelles» i dins el marc de la trenta-quatrena edició del Saló es van recórrer els vuit grans gèneres de la literatura com són l'amor, l'aventura, la por, la història, l'humor, la ciència-ficció, el realisme, el misteri i el terror. També es va organitzar una exposició dedicada a Pedrolo i al seu Mecanoscrit del segon origen.

L'any 2019 va ser el torn del 35è Saló del Llibre Infantil i Juvenil de Catalunya i va tenir com a eix central l'aigua. Es va parlar del tema des dels diversos punts de vista des dels quals la literatura I'ha tractat: aigua per beure, nedar, jugar, pintar, regar, cuinar, relaxar-se, admirar, viatjar, etc.

\section{- Biblio(R)evolució de la Fundació Bofill}

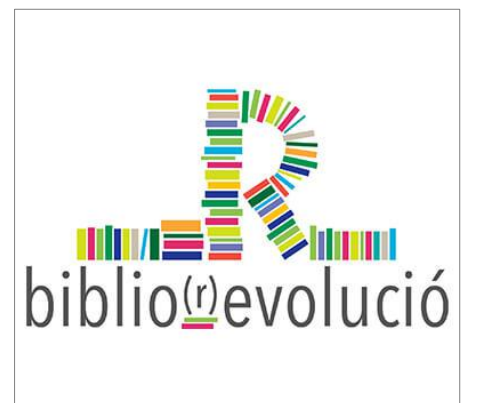

La Fundació Bofill va promoure una acció molt potent que va abastar trenta centres educatius de Catalunya per repensar els usos de la biblioteca com un agent que respon als reptes actuals de l'educació.

Es va generar un debat força ric entre la comunitat educativa sobre el paper clau de la biblioteca escolar en tant que agent de transformació educativa, mitjançant processos participatius i creatius, que van mobilitzar, durant sis mesos, tota la comunitat educativa en pro del repte plantejat.

El repte que plantejava la Biblio(R)evolució a la comunitat educativa va ser definir i cocrear fórmules innovadores que integrin la biblioteca escolar com un agent que respongui als reptes actuals de l'educació. Els trenta centres seleccionats, escoles $\mathrm{i}$ instituts implicats, van treballar de valent $\mathrm{i}$ van dedicar les hores que calien per afinar cadascun en el seu repte concret.

En aquest sentit, l'aposta de la Fundació va reforçar projectes que disposaven d'una dosi enorme d'il.lusió i voluntat de millora. D'alguna manera, van fer una feina que podria servir d'inspiració al Departament d'Ensenyament i animar-lo a fer quelcom de semblant però d'abast més ampli o general.

Un altre efecte de la crida bibliorevolucionària va ser visibilitzar la biblioteca escolar com a agent de transformació educativa.

\section{La Biblio(R)evolució podria servir d'inspiració al Departament d'Ensenyament $i$ animar-lo a fer quelcom de semblant però d'abast més ampli o general}


De manera resumida, la composició dels trenta centres educatius seleccionats va ser la següent:

- Etapa educativa: quinze centres educatius d'infantil i primària $i$ quinze centres de secundària o mixtos.

- Titularitat: vint-i-set centres públics i tres centres concertats.

- Territori: vint-i-dos centres de la demarcació de Barcelona (Barcelona, Cornellà de Llobregat, el Masnou, el Prat de Llobregat, Esplugues de Llobregat, Granollers, les Masies de Voltregà, I'Hospitalet de Llobregat, Ripollet, Terrassa, etc.), cinc de Girona (Banyoles, l'Escala, Porqueres, Roses), dos de Tarragona (Tarragona i Reus) i un de Lleida (Cervera).

Tot el material elaborat, la informació i les publicacions derivades es poden consultar i descarregar al web de la Fundació Bofill.

\section{- Matinal Bibliomèdia}

L'any 2018 es va organitzar la Fira de les Biblio(r)evolucions, una jornada que organitza el grup Bibliomèdia, adscrit als Moviments de Renovació Pedagògica. Es van presentar les accions que algunes escoles i instituts van desenvolupar en el marc de la «Crida» organitzada per la Fundació Bofill. La trobada va tenir lloc a l'Escola Garbí-Pere Vergés de Badalona.

L'any 2019 va tenir lloc a la Casa del Mar de Barcelona. Amb el títol «Miscel-lània» es va presentar un ventall de temes variats com «La formació per treballar la lectura» a càrrec de Mònica Badia, "Com la biblioteca escolar i la pública es poden organitzar» presentat per Gisela Ruiz, "Com fomentar la lectura emprant les eines digitals» a càrrec d'Albert Correa i, finalment, una lectura en diagonal de les noves directius de I'IFLA que va fer Júlia Baena, del Grup de Treball de Biblioteques Escolars del COBDC.

\section{- FLIC Festival}

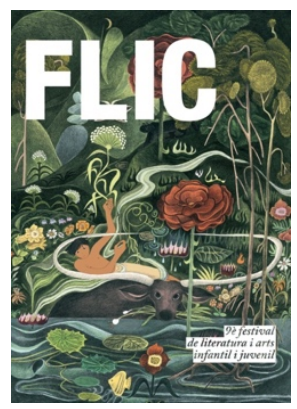

El FLIC és un festival d'accions, experiències i creació literària que convida les famílies, escoles i professionals a gaudir de la literatura i les arts, apostant per la innovació i l'experimentació en els diversos formats culturals.

L'any 2018 se'n va organitzar la vuitena edició amb el títol «Literatures en joc» i van ser-hi presents escriptors i il.lustradors de prestigi com Katsumi Komagata, Madalena Matoso, David Wiesner, Chris Haughton o Sophie Van der Linden, entre d'altres. Va tenir lloc a Barcelona, Madrid i Vic.

La novena edició es va anomenar «Read on» i es va centrar a parlar sobre literatura i creació, amb xerrades específiques i d'altres de més generalistes. Entre les xerrades específiques, va destacar la presentació del projecte europeu «Engage!», liderat pel PEN Català. Aquest projecte va

FLIC és un

festival d'accions, experiències $i$ creació literària que convida les famílies, escoles i

professionals a gaudir de la literatura i les arts 
recollir bones pràctiques de foment del gust lector i de propostes artístiques literàries dirigides a joves. De les xerrades generalistes, van ser molt celebrades les presentacions de Suzy Lee i d'Emily Hughes.

\section{- VI Congrés de Literatura Infantil i Juvenil Catalana, Llegir per Llegir}

El VI Congrés, organitzat per l'Associació d'Escriptors en Llengua Catalana, va tenir lloc al Pati Llimona de Barcelona els dies 30 de novembre i 1 de desembre de 2018.

$\mathrm{Hi}$ van haver moltes intervencions aplegades en quatre taules rodones. Sota el paraigua de la pregunta mare "Llegim per llegir?», van girar la majoria de les reflexions dels ponents. A la primera taula rodona, "Tendències i fenòmens actuals de la literatura infantil i juvenil catalana», van participar l'editor Jordi Martín, l'escriptora Care Santos, la llibretera Irene Tortós-Sala i l'escriptor i arquitecte Jaume Valor. La segona, "Com parlem d'allò que no es parla? Tabús en la literatura infantil i juvenil», va aplegar els pensaments de l'escriptor Txabi Arnal i la mestra Raquel Pueyo. En la tercera, "Gèneres literaris invisibles», hi van intervenir l'escriptor i psicòleg Saïd El Kadaoui, el poeta Miquel Àngel Llauger i l'actriu i creadora Carla Rovira. La quarta taula rodona, "Contagiar la literatura infantil i juvenil. Prescripció i difusió» va donar veu a la llibretera Núria Cárcamo, al professor Josep Ramon Cerdà, a la bibliotecària Anna Herráez i al presentador del programa de literatura infantil i juvenil Llegir per sentir de Ràdio Vilafranca, Josep Maria Soler.

La ponència inaugural la va pronunciar l'escriptor Josep Maria Badal amb el títol "És l'arbre que passa pel meu poble» en què reflexionava sobre l'origen i la necessitat del llenguatge.

\section{- Trobada de joves lectors}

La Institució de les Lletres Catalanes i el fòrum virtual Què llegeixes? van organitzar la IV Trobada de Joves Lectors, el 30 de juny de 2018, a l'espai Arts Santa Mònica, de Barcelona. Hi va haver intercanvi d'experiències entre lectors, escriptors, professors, editors, llibreters, bibliotubers, bloguers, prescriptors lectors, bibliotecaris $i$ altres actors que intervenen en el foment de la lectura entre els joves.

La jornada es va obrir amb una intervenció inicial de la consellera de Cultura, Laura Borràs. Anna Maria Villalonga, professora de la Universitat de Barcelona i comissària de l'Any Pedrolo, va oferir la conferència «Manuel de Pedrolo, l'escriptor que no té final». En la taula rodona amb escriptores hi van participar Maite Carranza, Maria Carme Roca i Muriel Villanueva, que van parlar sobre "Llegir i després escriure. Els referents» amb la moderació de Joan Portell de la revista Faristol i escriptor de literatura infantil i juvenil.

També hi va haver una taula rodona de joves lectors que van comentar el panorama actual pel que fa a l'evolució de la relació entre joves, lectura i xarxes. Van intervenir-hi Àfrica Bonet (de Cuinant Literatura Vlog), Marta Botet (de Recomanacions de llibres), Marta Meneu-Borja (de la Prestatgeria
La Trobada de Joves

lectors facilita

l'intercanvi

d'experiències entre

lectors, escriptors,

professors, editors,

llibreters,

bibliotubers,

bloguers,

prescriptors lectors,

bibliotecaris i altres

actors que

intervenen en el

foment de la lectura

entre els joves 
de Marta), ínigo Ovejero (de culturadeibecquer) i Pol Salvador (de Poliver) amb la moderació d’Ester F. Matalí.

Òscar Andreu, guionista, comunicador i humorista, va ser el protagonista $d^{\prime}$ 'un diàleg amb Gemma Ventura en què es va parlar de llegir i escriure.

\section{- Jornada de literatura i creixement emocional}

L'Institut de la Infància de Sant Cugat del Vallès va continuar amb la seva tasca d'acostar els llibres als infants, especialment als de la franja entre zero i tres anys. Va organitzar nombrosos encontres, jornades i escoles d'estiu, en models de formació variats i molt estimulants. Dues de les trobades van ser:

La 7a Escola d'Estiu «Fòrum Literatura i Infància», organitzada els dies 9, 10 i 11 de juliol de 2019 al Monestir de Sant Cugat, amb un programa innovador que permetia accedir a més de quinze propostes: xerrades col-loqui, tallers inspiradors, presentacions de novetats amb autors $\mathrm{i}$ il-lustradors; experiències per portar a l'aula o transformar l'escola i omplirla de contes, trobades amb editors que et descobrien nous recursos, $\mathrm{i}$ visites als espais Minimons creats per l'equip de l'Institut de la Infància,

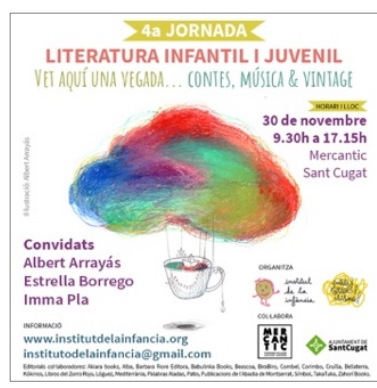

etc. amb exposicions temàtiques de llibres.

La 4a Jornada de Literatura Infantil i Juvenil, amb el títol «Vet aquí una vegada... contes, música \& vintage», va tenir lloc el 30 de novembre al Mercantic de Sant Cugat, amb la participació d'Estrella Borrego, editora i especialista en literatura infantil i juvenil, i d'Albert Arrayás, il.lustrador i autor d'àlbums, tallers d'art i ioga,

\section{- III i IV Fira del Llibre Infantil i Juvenil de Girona}

Són una iniciativa de la Fundació Llibreria Les Voltes. L'any 2018 se'n va organitzar la tercera edició. A més d'accions com un concert «Música i literatura», visites a tallers literaris i la "Batalla Freestyle», hi va haver una conferència impartida per Anna Manso amb el títol: «En defensa de la literatura infantil i juvenil», adreçada a mestres, professorat, educadors, bibliotecaris, pares i mares.

L'any 2019 va tenir lloc la quarta edició en què es van programar un seguit d'activitats per a tots els públics: "L'Aran i les paraules màgiques», a càrrec d'Anna Godoy i Ivan Godoy; "La Bruna aprèn a deixar-se ajudar», a càrrec d'Anna Ferrer, i la presentació d'una guia sobre l'alimentació per a infants i adults amb càncer, a càrrec de Pilarín Bayés i Antonieta Barahona, entre altres propostes lúdiques.
L'Institut de la

Infància de Sant

Cugat del Vallès continua amb la

seva tasca d'acostar els Ilibres als infants, especialment als de la franja entre zero $i$ tres anys 


\section{- La Setmana del Llibre en Català}

Finalment, sembla que la Setmana ha trobat la ubicació i les dates idònies per consolidar la Fira que el país es mereix, amb la satisfacció d'haver assolit els objectius proposats.

A la trenta-sisena i la trenta-setena edicions es va aixoplugar la concentració més gran de títols diferents editats en català, es va donar visibilitat als llibres, revistes i publicacions periòdiques en català, als seus autors, editors, traductors, llibreters i distribuïdors. Es va continuar apostant per la creació de nous lectors i potenciant el foment de la lectura en català $\mathrm{i}$ tot plegat es va fer teixint complicitats amb les biblioteques públiques, les entitats culturals, les empreses privades, les institucions públiques $\mathrm{i}$ altres actors socials. En destaca la gran presència de les editorials adreçades a un públic infantil.

\section{- Jornada Biblioteca i Comunitat Educativa}

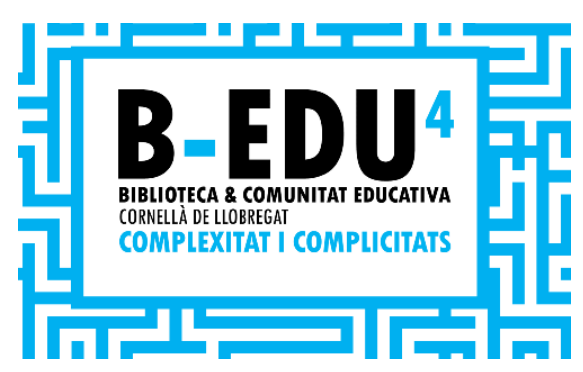

La Quarta Jornada Biblioteca i Comunitat Educativa va tenir lloc el 18 de novembre de 2019 a l'Auditori Sant Ildefons de Cornellà de Llobregat. El títol triat en aquesta ocasió va ser «Complexitat i complicitats» i feia referència que vivim en entorns complexos i contingents on les diferents visions i accions dels nostres equipaments públics - biblioteques i centres educatius - són com un mostrari de les diferents interpretacions d'un món globalitzat.

Entre els debats i opinions que es van exposar, van destacar les veus de Joan Artigal, director de l'Institut Escola Trinitat Nova, i Agustí Montardit, coordinador de la biblioteca comunitària del mateix institut escola, que van aportar la visió sobre la complexitat del compromís en el marc d'un projecte pedagògic, comunitari i lector en entorns vulnerables.

Jaume Funes, psicòleg i educador, va ajudar a visualitzar l'abast que suposa educar per explicar als adolescents el món complex en què vivim.

Anna Juan, doctora en Antropologia Social i Cultural i màster en Llibres i Literatura Infantil, va contribuir a mostrar-nos els elements que hauríem de tenir en compte a l'hora d'ajudar els infants i els mediadors a triar literatura en temps complexos.

\subsection{Premis}

Al llarg d'aquests dos anys s'han atorgat nombrosos premis literaris per fomentar el coneixement de la literatura infantil i juvenil. Normalment, els

\section{La Setmana del}

Llibre en Català

sembla que ha

trobat la ubicació $i$

les dates idònies per

consolidar

la Fira que el país

es mereix 
Ilibres premiats tenen bona difusió, solen ser de qualitat i arriben a molts més infants $i$ joves. Els autors tenen una bona oportunitat d'arribar a un públic més ampli, a través de la promoció que se'n fa a les revistes especialitzades $i$ altres mitjans, especialment les xarxes socials.

Alguns dels premis literaris més celebrats i prestigiosos que s'han lliurat en aquests dos anys han estat els següents:

\section{Any 2018}

13è premi de literatura infantil Atrapallibres convocat pel ClijCAT: Categoria 9 anys: Doyon, Patrick. El lladre d'entrepans. Cruïlla. Categoria 10 anys: Haig, Matt. Un noi anomenat Nadal. Estrella Polar. Categoria 11-12 anys: Carranza, Maite. La pel.lícula de la vida. Cruïlla.

22è premi de literatura Protagonista Jove, convocat pel ClijCAT: Categoria 13-14 anys: Reinhardt, Dirk. Train kids. Pagès.

Categoria 15-16 anys: Niven, Jennifer. Aquí és on tot comença. Grup editorial 62 (Fanbooks).

34è premi Vaixell de Vapor de literatura infantil:

Lienas, Gemma. Jo, en Watson i l'armari de la Jacqueline. Cruïlla.

28è premi Gran Angular de literatura juvenil: Nel·lo, David. La segona vida del Marc. Cruïlla.

Premi Josep M. Folch i Torres de literatura infantil: Franquet, Núria. La Liang dins el quadre. La Galera.

Premi Crítica Serra d'Or (Publicacions de l'Abadia de Montserrat): Categoria infantil: Benegas, Mar. I aquí dins, qui hi ha? Categoria juvenil (creació): Carranza, Maite. Una bala per al record. Categoria juvenil (coneixements): Medina, Víctor. Ports.

Premi Joaquim Ruyra de narrativa juvenil: Carranza, Maite. L'alè del drac. La Galera.

Premi Edebé de literatura juvenil: Lozano, David. Desconeguts. Edebé.

\section{Any 2019}

14è premi de literatura infantil Atrapallibres convocat pel ClijCAT: Categoria 9 anys: Copons, Jaume. No llegiré aquest llibre. La Galera. Categoria 10 anys: Vallverdú, Josep. Bestiolari 2. Fil d'Aram. Categoria 11-12 anys: Aguilar, Laia. Wolfgang (extraordinari). Columna.

23è premi de literatura Protagonista Jove:

Categoria 13-14 anys: Carranza, Maite. Una bala per al record. Grup Promotor Santillana.
S'han atorgat

nombrosos premis

literaris per

fomentar el

coneixement de la

literatura infantil $i$

juvenil 
Categoria 15-16 anys: Lozano, David. Desconeguts. Edebé

35è premi Vaixell de Vapor de literatura infantil:

Guiluz, Teresa. L'extraordinari cas dels objectes apareguts. Cruilla.

29è premi Gran Angular de literatura juvenil:

Bayo, Emili. Prop de les bombes. Cruilla.

Premi Crítica Serra d'Or (Publicacions de l'Abadia de Montserrat):

Categoria infantil: Nogués. Àlex. Un pèl a la sopa.

Categoria juvenil (creació): Parera, Núria. La maleta.

Categoria juvenil (coneixements): Bestard, Aina. Naixements bestials.

Premi Joaquim Ruyra de narrativa juvenil:

Mata, Toni. Nascuts per ser breus. La Galera.

Premi Edebé de literatura infantil:

Carranza, Maite. Safari. Edebé.

\section{PUBLICACIONS I REVISTES}

Aquest bienni ha estat prolífic en publicacions d'assaigs que aprofundeixen en el món de la literatura infantil i la juvenil. Destaquem els següents:

Joan Portell i Gisela Ruiz expliquen a les Publicacions de l'Abadia de Montserrat Adolescents i lectura. El binomi fantàstic, un títol que juga amb l'optimisme rodarià. Entremig d'uns capítols prou amens, recomanen bons llibres, en una selecció pensada i que no hauria de faltar a les biblioteques dels instituts.

El llibre està estructurat en set capítols, el segon, el quart i el cinquè dels quals sobresurten pel seu interès (lectura $\mathrm{i}$ adolescents; adolescents, lectura $\mathrm{i}$ institut, $\mathrm{i}$ lectura adolescent $\mathrm{i}$ biblioteques).

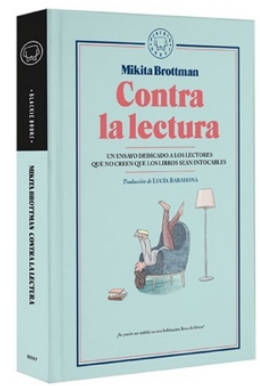

Mikita Brottman, a Contra la lectura, editat per Blackie Books, presenta unes reflexions on pretén fer-nos adonar d'alguns fets que semblen inqüestionables com que la presència o absència de llibres físics ens revela com és una persona i que algunes formes de lectura són millors que d'altres. També argumenta que la literatura pot transformar-nos si llegim el llibre apropiat en el moment adequat.

Ana Lartitegui, a Alfabeto del libro de conocimientos. Paradigmas de una nueva era, ens fa un recorregut per les paraules que expliquen com ha canviat la literatura de coneixements adreçada a infants $i$ joves.

\section{Aquest bienni ha estat prolific en publicacions d'assaigs que aprofundeixen en el món de la literatura infantil i la juvenil}

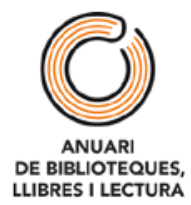


Freddy Gonçalves ha publicat La nostalgia del vacío, un llibre que ens parla de com els adolescents construeixen el sentiment de pertinença gràcies a les lectures: s'apropien dels seus trets per constituir la seva identitat.

La lectura. Entre el paper i les pantalles, de Gemma Lluch, analitza com les pantalles i internet han modificat la manera d'entendre la lectura.

Teresa Colomer, Mireia Manresa, Lucas Ramada i Lara Reyes van publicar Narrativas literarias en educación infantil y primaria, un llibre que tracta sobre les narracions orals (en paper i en pantalla) partint de la pregunta sobre què volem que els infants aprenguin amb els contes a l'escola.

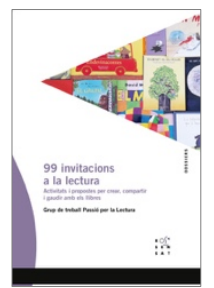

99 invitacions a la lectura, un dossier elaborat pel grup de treball Passió per la Lectura de l'Associació de Mestres Rosa Sensat, presenta noranta-nou invitacions per crear, compartir i gaudir amb la lectura des d'un vessant lúdic. Les activitats i propostes de treball, ordenades per cicles escolars, acosten els llibres des d'angles diferents.

El llibre Mot per mot. Literatures d'infant, de Roser Ros, convida els adults lectors a practicar l'art de la literatura amb els infants des de la seducció i la provocació. En el llibre, l'autora situa i defineix la mediació literària, les literatures d'infants i l'oralitat, i també mostra un munt d'històries per explicar i escoltar.

L'editora Arianna Squilloni ens explica a En la oficina del editor. Apuntes, técnicas y reflexiones com és el dia a dia d'una petita empresa editorial de llibre per a infants i joves. S'ocupa de detalls del seu ofici que van des del càlcul del preu del llibre fins a com encomanar l'entusiasme per la lectura.

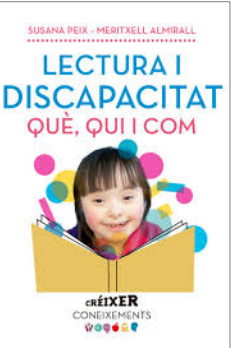

A Lectura i discapacitat, Susana Peix i Meritxell Almirall volen conscienciar professionals i famílies de la importància de contribuir a la inclusivitat perquè els més petits accedeixin a la lectura en igualtat de condicions. Es tracta d'un llibre per trobar resposta i assessorament sobre tot allò relacionat amb els infants, la lectura i les persones amb discapacitats motores, sensorials o cognitives.

\section{Revista GUIX}

Des del febrer de 2019 la revista GUIX inclou una secció fixa anomenada "Viure l'escriptura» on s'exposen experiències escolars relacionades amb l'escriptura de textos amb la intenció d'oferir pistes i pràctiques que ens reconcilien amb l'escriptura perquè tots els infants tenen coses a dir $\mathrm{i}$ només cal trobar les paraules oportunes perquè la por al que pensin els altres, la por a equivocar-se i els dubtes, s'esvaeixin. En aquests articles $s^{\prime}$ exposen idees que ajuden a trobar el plaer d'escriure en llibertat $i$ ho acompanyen de textos literaris que poden servir de model i referència. Els
Des de 2019 la revista GUIX inclou una secció on s'exposen experiències escolars relacionades amb l'escriptura de textos amb la intenció d'oferir pistes i pràctiques que ens reconcilien amb l'escriptura 
diferents escrits abasten tota mena de textos (narratius, poètics, instructius, etc.).

\section{Revista Faristol}

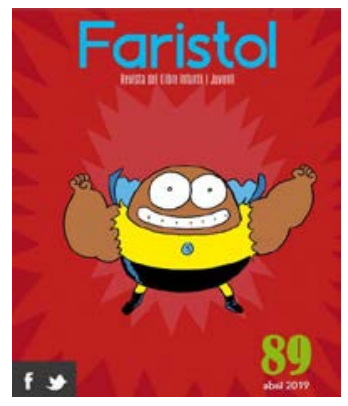

La revista Faristol posa veu a les activitats que organitza el ClijCAT i cada any publica dos números en format paper.

En aquest període han publicat quatre números interessants, dedicats cadascun d'ells a un tema. Així, el número 87 (abril de 2018), sota l'epígraf «Jugar amb la materialitat del llibre» abordava com les característiques físiques dels àlbums poden estar al servei de la narració. Contenia, també, una entrevista amb l'il·lustrador nord-americà David Wiesner i un reportatge sobre les biblioteques mòbils arreu del món.

El número 88 (novembre de 2018) va estar dedicat als personatges femenins. Es titulava «Elles són les protagonistes» i plantejava diverses qüestions entorn dels llibres protagonitzats per personatges femenins, des d'una visió crítica i actual. Incloïa, també, una tria de deu títols infantils i juvenils amb nenes i noies com a protagonistes.

El número 89 (abril de 2019) va estar dedicat al còmic. "Va de còmic!» contenia articles sobre la tradició del còmic català, el panorama actual, el seu valor com a eina per fomentar la lectura, etc. També hi ha una selecció de deu còmics que parlen de compromís social.

La revista Faristol 90 (novembre de 2019) tracta sobre «El poder de la paraula escrita (ben escrita)» i conté articles que parlen de l'art d'escriure bé per a infants i joves. També, una tria de deu llibres infantils i juvenils que juguen amb les paraules, abecedaris, una fàbrica de contes, definicions inventades, etc.

\section{TENDẼNCIES}

La progressió del panorama lector al nostre país no és gaire encoratjadora. Es llegeix poc i els pares, per exemple, opten per portar els fills a activitats extraescolars esportives abans de freqüentar regularment la biblioteca més propera. Resulta sorprenent i contrasta amb l'aposta que els organismes oficials fan per donar impuls a plans de lectura conscients que els seus efectes beneficiosos estan explicitats en els diversos manifestos que la UNESCO (Organització de les Nacions Unides per a l’Educació, la Ciència i la Cultura) ha anat promulgant $i$ en els quals ens recorden que un llibre afegeix vida a la vida i que les biblioteques són espais adequats per conservar i ordenar els llibres, on els nens poden accedir a la seva lectura.
La materialitat del

llibre, els

personatges

femenins, el còmic i

el poder de la

paraula escrita

han estat els temes

que han centrat

l'atenció de la

revista Faristol en

aquests dos anys 
Així les coses, no és d'estranyar que en els rànquings de països lectors estiguem lluny de països com Finlàndia, Noruega, Holanda, Letònia, els Estats Units, Singapur, etc., alguns amb característiques compartides. El clima, per exemple, que convida a passar més hores reclosos pot ser un dels motius. L'aposta per un sistema educatiu que cregui en l'educació humanista, sol ser-ne un altre. També hi influeix que són països pròspers, rics. A Singapur, un dels països més lectors, tenen una política de govern que ha estat clau per impulsar una xarxa extraordinària de biblioteques $\mathrm{i}$, especialment, el suport a la tecnologia digital. Així, les biblioteques públiques de Singapur (The Public Libraries Singapore o PLS) són molt atractives físicament $\mathrm{i}$ amb un funcionament modern i professional que fa que les persones les visitin a la recerca d'aprenentatge, tinguin l'edat que tinguin. Hi ha una xarxa de vint-i-sis biblioteques públiques (incloses tres biblioteques regionals) ubicades convenientment a tot Singapur que tenen la missió principal de connectar les persones amb la resta de la comunitat. El Govern disposa d'un ministeri específic que anomenen Ministeri de Comunicacions i Informació $(\mathrm{MCl})$, que és l'encarregat de supervisar el desenvolupament dels sectors de la tecnologia informàtica, la seguretat cibernètica i els mitjans de comunicació, la biblioteca nacional, els arxius nacionals i les biblioteques públiques, així com les polítiques d'informació i comunicació públiques del Govern. A Singapur tenen un potent moviment nacional de lectura per animar els singapuristes a llegir més, a llegir durant més temps i a llegir junts.

Que la lectura és útil en la nostra societat està clar i sobta comprovar que hi ha moviments positius com l'obertura de noves llibreries, noves editorials i, sobretot, nous entorns digitals lectors. En canvi, les polítiques públiques no fan una aposta decidida i ferma per aconseguir que les dinàmiques estructurals que funcionen des de fa molts anys puguin créixer o, si més no, viure amb una certa tranquil.litat i bonança econòmica. No s'acaba d'entendre com les noves tendències en el sector de llibre (en format paper i digital) es multipliquen i es creen nous paràmetres, nous camins d'accedir a la lectura i a la cultura, noves maneres d'elaborar la informació i compartir-la i, en canvi, continuem tenint una xarxa poc articulada entre el sector públic $i$ el privat. Aquest fet debilita la producció editorial i ens allunya cada vegada més dels països punters abans mencionats. Si, a més, hi afegim les crisis econòmiques que, amb certa freqüència, ens toca viure, el panorama no pot ser gaire esperançador.

Potser els temps que vindran seran millors. Posats a somiar, les biblioteques escolars començaran a ser més ben valorades i dotades de personal, als telenotícies hi haurà una secció cultural on el llibre tingui presència, els autors de literatura infantil $i$ juvenil podran viure de la seva obra i quan es passin proves de lectura als nostres alumnes, comprovarem com són capaços de comprendre el que s'amaga entre línies i d'inferir el que l'autor ens vol dir perquè serà senyal que són millors lectors, més crítics, més savis i més humans. Somnis.

De moment, celebrem com cal el centenari de Gianni Rodari.
Es Ilegeix poc i els

pares, per exemple, opten per portar els fills a activitats extraescolars esportives abans de freqüentar regularment la biblioteca més propera 


\section{BIBLIOGRAFIA}

VI Congrés de Literatura Infantil i Juvenil. Llegir per llegir (2019). Barcelona: AELC. (Quaderns Divulgatius, 62).

$<$ https://www.escriptors.cat/sites/default/files/2019-05/quadern-62-

congres-literatura-infantil-aelc.pdf.pdf>.

Brottman, M. (2018). Contra la lectura. Barcelona: Blackie Books. 168 p. ISBN 978-84-17059-54-5.

Colomer, T.; Manresa, M.; Ramada Prieto, L.; Reyes López, L. (2018). Narrativas literarias en educación infantil y primaria. Madrid: Síntesis. 212 p. ISBN 978-84-91712145.

Consell Superior d'Avaluació del Sistema Educatiu (2019). L'avaluació de $4 t$ d'ESO 2019 [Barcelona]: Generalitat de Catalunya. Departament d'Ensenyament. 78 p. (Quaderns d'avaluació; 43). ISSN Electrònic 2014797X.

$<$ http://csda.gencat.cat/ca/arees d actuacio/publicacions/quaderns avalu acio/quaderns-avaluacio-43/>.

Consell Superior d'Avaluació del Sistema Educatiu (2019). L'avaluació de sisè d'educació primària 2019 [Barcelona]: Generalitat de Catalunya. Departament d'Ensenyament. 67 p. (Quaderns d'avaluació; 44). ISSN electrònic 2014-797X.

<http://csda.gencat.cat/ca/arees d actuacio/publicacions/quaderns avalu acio/quaderns-avaluacio-44/>.

Consell Superior d'Avaluació del Sistema Educatiu (2020). Programa per a I'Avaluació Internacional de l'Alumnat (PISA). Resultats de Catalunya 2018. [Barcelona]: Generalitat de Catalunya. Departament d'Ensenyament. $44 \mathrm{p}$. (Quaderns d'avaluació; 45). ISSN electrònic 2014-797X.

$<$ http://csda.gencat.cat/ca/arees d actuacio/publicacions/quaderns avalu acio/quaderns-avaluacio-45/>.

Fernández de Gamboa Vázquez, K. (2019). A través del nuevo milenio y lo que el lector literario encontró allí: la narrativa infantil para lectores de 8 a 10 años. Tesi doctoral dirigida per Teresa Colomer. Universitat Autònoma de Barcelona. <https://ddd.uab.cat/record/203420>.

Generalitat de Catalunya. Departament de Cultura (2017). Pla de lectura 2020. Barcelona: Generalitat. Volum 1. Pla de lectura 2020, 93 p.

$<$ https://cultura.gencat.cat/web/.content/sscc/pla-lectura-

2020/documents/A4 PlaLectura-Vol 1.pdf $>$.

Generalitat de Catalunya. Departament de Cultura (2017). Pla de lectura 2020. Barcelona: Generalitat. Volum 2. Per què llegir, 93 p.

$<$ https://cultura.gencat.cat/web/.content/sscc/pla-lectura2020/documents/A4 PlaLectura-Vol 2.pdf>.

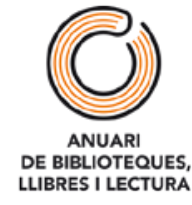


Grup de treball Passió per la Lectura (2019). 99 Invitacions a la lectura: Activitats i propostes per crear, compartir i gaudir amb els llibres. Barcelona: Associació de Mestres Rosa Sensat. 152 p. ISBN 978-8412009668.

Lartitegui, Ana G. (2018). Alfabeto del libro de conocimientos: paradigmas de una nueva era. Zaragoza: Pantalia. 125 p. (Cuadernos Hexágono; 6). ISBN 978-84-942456-6-4.

Lluch, G. (2018). La lectura. Entre el paper i les pantalles. Vic: Eumo. 168 p. ISBN 978-84-9766-631-2.

Peix, S.; Almirall, M. (2019). Lectura i discapacitat. Què, qui i com. Barcelona: Publicacions de l'Abadia de Montserrat. 90 p. ISBN 978-84-9191056-5.

Portell, J.; Ruiz, G. (2019). Adolescents i lectura: el binomi fantàstic. O com acostar, treballar $i$ promocionar la lectura entre els joves. Barcelona: Publicacions de l'Abadia de Montserrat. 144 p. ISBN 978-84-9191-060-2.

Ros, R. (2019). Mot per mot. Literatures d'infant. Barcelona: Associació de Mestres Rosa Sensat. 144 p. ISBN 978-84-12009606.

Silva, Freddy Gonçalves da (2018). La nostalgia del vacío: la lectura como espacio de pertenencia en los adolescentes. Zaragoza: Pantalia. 108 p. (Cuadernos Hexágono; 7). ISBN 978-84-942456-5-7.

Squilloni, A (2019). En la oficina del editor. Apuntes, técnicas y reflexiones. Bilbao: Pantalia. 192 p. ISBN 978-84-942456-7-1. 


\section{Disponible a:}

https://revistes.ub.edu/index.php/Anuari-BLL/article/view/32267

Centelles, Jaume. «La lectura entre els infants i joves a Catalunya (2018-2019)».

Anuari de Biblioteques, Llibres i Lectura, vol. 6 (2020), p. 89-110.

DOI 10.1344/ABLL.2020.6.007

Llicència Creative Commons

Reconeixement - NoComercial - SenseObraDerivada

(by-nc-nd): No es permet un ús comercial de l'obra

original ni la generació d'obres derivades. 


\title{
ANUARI
}

\section{DE BIBLIOTEQUES,}

\section{LLIBRES I LECTURA}

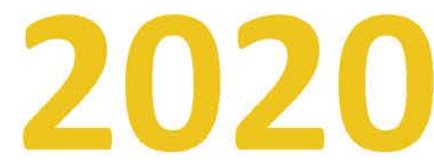

\section{Editors}

\author{
Lluís Agustí \\ Maite Comalat
}

